Article Citation Format Ogunrinola O.B., Olalere N.A., Nwosu E.U. and Onaifoh G.N (2019): Minimizing the Wastage of Electrical Energy at Utilization Level Journal of Digital Innovations \& Contemp Res. In Sc., Eng \& Tech. Vol. 7, No. 1. Pp 23-32 $\underline{\text { Article Progress Time Stamp }}$

Article Type: Research Article Manuscript Received: $7^{\text {th }}$ Dec. 2018 Review Type: Blind

Final Acceptance: $8^{\text {th }}$ Feb, 2019

Article DOI: dx.doi.org/10.22624/AIMS/DIGITAL/V7N1P3

\title{
Minimizing the Wastage of Electrical Energy at Utilization Level
}

\author{
Ogunrinola O.B. ${ }^{1}$, Olalere N.A. ${ }^{2}$, Nwosu E.U. ${ }^{3}$ and Onaifoh G.N. ${ }^{4}$ \\ ${ }^{1,2,2,4}$ Dept. of Industrial Maintenance Engineering \\ Yaba College of Technology \\ Yaba-Lagos. \\ E-mail: naolalere@yahoo.com \\ Phone: +2348058484851
}

\begin{abstract}
The high cost of fossil fuels coupled with climate change and global warming concerns have instigated a tremendous demand for renewable energy all over the world. Indisputably, the most widely used renewable energy sources generate direct current (DC), hence inverters are employed to produce the required alternating current (AC). However, during the inversion process a significant amount of the electrical energy is lost. This paper identifies the wastage of electrical energy associated with the use of inverters for powering DC loads from DC sources, like the solar PV system. Two experiments were conducted and a comparative analysis of the results was made. Some DC loads were connected to a battery via an inverter and the same loads were later connected to the battery without the inverter. The two set of loads were operated for the same durations and the depreciating terminal voltages of the battery in both cases were recorded at regular time intervals. At the end of the experiments, it was observed that the battery retained a higher voltage when the loads were connected directly. A number of trials was carried out and there was no discrepancy in the outcomes. Availability of renewable energy sometimes relies on the weather, so batteries are often needed for the energy storage. Improvements on the life span and efficiency of this storage medium or a discovery of cheaper alternatives would be a laudable innovation.
\end{abstract}

Keywords: Energy, Inverter, Loads, Solar.

\section{INTRODUCTION}

Electrical energy is an essential part of modern life. It has relieved us from hard labour. This form of energy is required for operations like heating, cooling, lighting, and refrigeration. Communication, tourism, education, health care, water supply, agriculture, security systems, entertainment/relaxation, and even public transportation systems are all influenced by electrical energy. The significance of electricity is most understood when it is not available even for just a short period. Almost all the domestic, commercial and industrial activities would be hindered without electricity. 
Therefore, the socio-economic development of any modern society depends largely on low cost, continuous and unlimited supply of electrical energy. Without electricity, the world will go back to primitive age. Due to its great relevance, there are always challenges in the generation, transmission, distribution, utilization, and most importantly, storage of electrical energy. The generation of electrical energy from fossil fuels (coal, oil, and natural gas) is not only expensive, but also causes air and water pollution, damage to public health, wildlife/habitat loss, global warming emissions, etc. each of which has adverse effects on the economy of a nation.

The use of renewable energy was thus preferable. This is the energy collected from renewable resources that are naturally replenished on a human timescale (Ellabban, 2014). These resources include sunlight, wind, rain, tides, waves, biomass, and geothermal heat. Renewable energy is always cheaper since the sources are abundant. At least one local source of renewable energy can typically be found at almost any location on the Earth's surface. Most of these sources are also inexhaustible, and affordable. However, this is not a liberty to waste the energy because there is a cost associated with the electrical energy generation. In addition, renewable sources also have environmental impacts, some of which are significant. With the increasing demand for renewable energy and advances in energy management, the solar PV system has become a common source of electrical energy in many homes and workplaces. It involves the use of solar panels to transform light radiations from the sun into electrical energy. When solar panels are exposed to sunlight they only generate DC voltage thus inverters are often used to change the produced DC voltage into AC. However, during the inversion process a significant amount of the electrical energy (DC) is lost (Schiermeier, et al, 2008). This paper identifies wastage of electrical energy, particularly at the utilization level, as a source of issues relating to the demand and supply of electrical energy.

In the use of renewable energy, batteries are often required for electrical energy storage because renewable sources are characterized by their temporal and spatial variability, which is in contrast to fossil fuels. The sun, for instance cannot be available for the entire twenty-four hours of a day. In a solar PV system, the batteries are expected to serve after sun sets or during some cloudy days. Wasting the stored energy through the use of inverters would get the batteries exhausted faster. This could constrain the user to fall back on the traditional fossil fuel generator, thus bringing back the problems associated with non-renewable energy sources. The type of appliances we choose to use on a particular type of supply (AC or DC) has direct impact on the electrical energy consumption because it determines the conversion losses that would be incurred. An increasing fraction of residential end-loads operates internally on DC power, but they are fed with AC power from the inverter as input. This supply has to be rectified and filtered to provide a smooth constant voltage (DC) capable of powering the electronic circuitry within the device. Hence, each appliance requires either an internal or an external AC to DC converter in order to operate at its correct DC voltage. These multiple conversion processes create heat losses both in working and standby modes (Garbesi et al, 2011). Therefore, eliminating undue voltage conversion from DC to AC by inverters will make a significant impact in reducing electrical energy wastage.

\subsection{Ways of Minimizing Electrical Energy Wastage}

Due to the penalty cost attached, a variety of conservative habits are being cultivated by individual to cut the proportion of their electrical energy that is wasted. Applying a "switch OFF when done" policy for all lights and electrical appliances/machines is one of such practices. A large percentage of the energy consumed due to lighting is also preserved by replacing the incandescent light bulbs with LED bulbs. Making it a priority to verify the energy consumption of any appliance before purchasing it has likewise been a good measure for acquiring only energy-efficient appliances. 


\section{MATERIALS AND METHODS}

In an existing solar PV system, the 12V, 200Ah battery was isolated after being fully charged and five number of DC loads namely: an LED bulb and television, a table fan, a home theatre, and a laptop were connected to the $230 \mathrm{~V}, 50 \mathrm{~Hz}$ output of the inverter (Figure 2.1). With each of the loads already in its ON state, the inverter was switched $\mathrm{ON}$ to run all the loads from the battery at the same time. The initial terminal voltage $(\mathrm{V})$ of the battery at the instant of switching $\mathrm{ON}$ the inverter was recorded as displayed on the voltmeter. The clock time at that moment was also recorded.

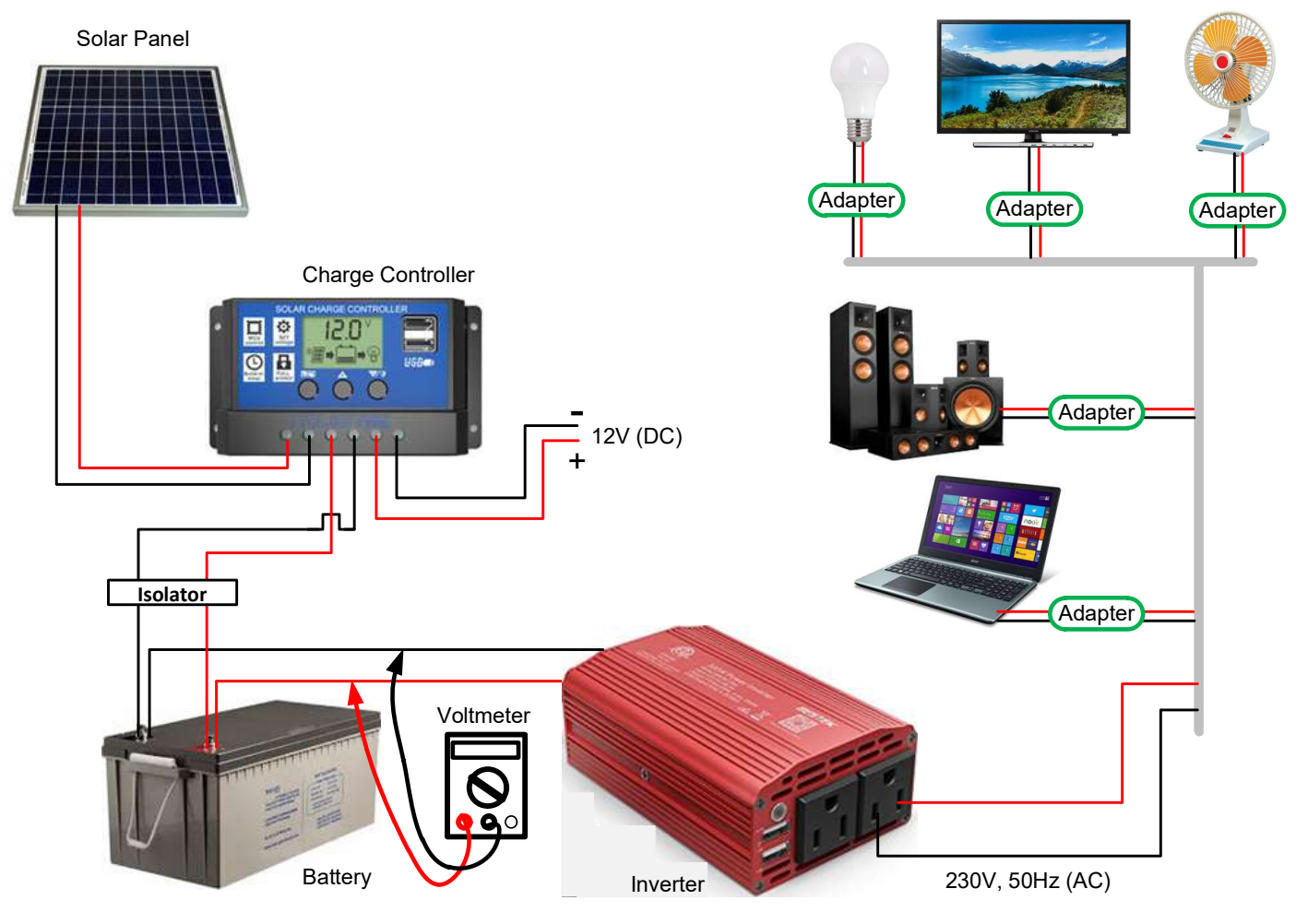

Figure 2.1: Wiring Layout for Experiment 1

As the battery is being discharged, new values of the terminal voltage were recorded every thirty minutes for six hours after which the inverter was switched OFF. A graph of the terminal voltage (V) against discharge time was plotted to obtain the discharge characteristic of the battery for the given loads (Figure 3.1). Although, each of the loads has internal adapter (AC to DC converter) with exception of the laptop, all the adapters were indicated on the wiring diagram to emphasis the rectification processes involved. To conduct the second experiment, the isolator was switch $\mathrm{ON}$ to resume charging of the battery. When the battery was fully charged again the entire process was repeated but without the inverter (Figure 2.2) and another plot of terminal voltage versus discharge time was obtained on the same axis depicting the discharge characteristic of the battery for the given load when inverter was eliminated. 
A comparative analysis of the two curves was made to identify the energy wastage associated with the use of an inverter for powering DC loads through a DC supply. Three trials were made for each of the two experimental setups on different days of a week at about $28^{\circ} \mathrm{C}$ but a significant discrepancy among each set of results was not observed.

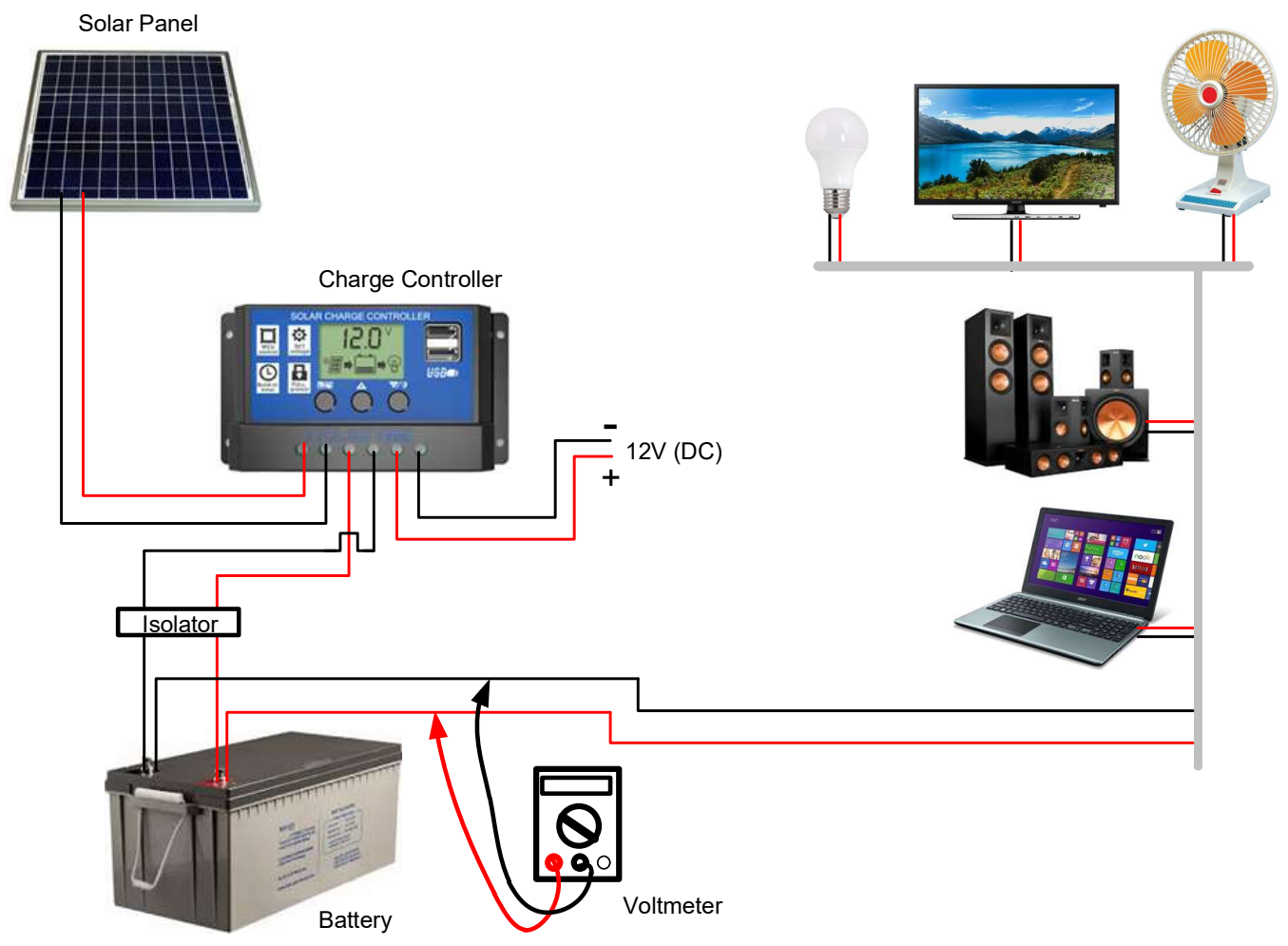

Figure 2.2: Wiring Layout for Experiment 2

\subsection{Description of Components}

The major materials used in this research include a solar panel, a charge controller, a battery, an isolator switch, AC adapters, a multimeter, connecting cables, battery clips, a thermometer, a table clock, and DC loads (an LED bulb and television, a table fan, a home theatre, and a laptop). Here is a brief explanation of some of these items and their selections as it affects the aim of this paper.

\section{I) Battery}

A $12 \mathrm{~V}, 200 \mathrm{Ah}$ deep cycle solar power battery was used. This is a lead-acid battery designed to be regularly deeply discharged using most of its capacity. It is designed to discharge up to $75 \%$ of its capacity. This depth of discharge varies with manufacturer and the construction of the battery. A deep cycle battery gives out a small amount of power over a long period in contrast with the regular battery which gives out a large amount of power over a short period. This battery attained precisely 13.8 volt when it was fully charged and about 24 hours after it was removed from the charger, the voltage settled at 12.6 volts which is referred to as the actual resting voltage of the battery. This is an indication that a battery may actually have higher capacity than its nominal rating. 


\section{II) Solar Panel}

This is a collection of solar cells, spread over a large area, that convert sunlight, which is free and inexhaustible, into electricity directly. Each of the solar cell is made from a semiconductor material such as silicon. Percentage of the light energy that can be converted into electricity (output of the panel) depends on the category of silicon used. This is about 12 to $19 \%$ for a mono-crystalline or polycrystalline silicon used in the first-generation solar panels. This percentage is reduced to between 5 and $11 \%$ for the secondgeneration solar panels where the solar cells are made of amorphous silicon. Although these panels are less expensive and more aesthetic, the first-generation solar panel was utilize in our experiment to facilitate recharging of the battery. The maximum electrical capacity that a solar cell can yield under ideal circumstances is expressed in watt peak $(\mathrm{Wp})$. A $12 \mathrm{~V}, 200 \mathrm{~W}$ solar panel was used. This rating indicates that it has a capacity to generate 200 watts of electricity per hour. The output voltage of a solar panel always fluctuates because the intensity of sunlight varies throughout the day. As a result of this, solar panels are embellished with more cells to compensate for times when the intensity of sunlight is low. A solar panel rated $12 \mathrm{~V}$ may actually be constructed with solar cells that can deliver up to $20 \mathrm{~V}$ just to ensure that the output of the panel does not drop below its rated value when there is low sunlight.

\section{III) Charge Controller}

For the solar panel to charge the battery, it is necessary to regulate the voltage and current coming from it in order to prevent the battery from overcharging or damage. The solar charge controller was therefore introduced. It takes in the fluctuating input from the solar panel and stabilize it to safely charge the battery. Although a solar inverter comes with a built-in charge controller, but the regular inverter was used in our experiment. The Maximum Power Point Tracking (MPPT) solar charge controller was used because of the following features which it possesses.

- Reverse Current Protection: The battery is often at higher potential when there is no sunlight and current will thereby tend to flow back from the battery to the solar panel.

- Voltage Detection: It automatically detects the battery voltage (e.g. $12 \mathrm{~V}$ or $24 \mathrm{~V}$ ) and regulates the voltage and current from the panel to suit charging of the battery.

- Short Circuit Protection: It protects the solar cells from any form of short circuit fault.

- It also monitors battery temperature to prevent overheating.

\section{IV) Battery Isolator Switch}

This is an electrical device that allows the flow of current in one direction. It was deliberately introduced for the purpose of this paper in order to completely disconnect the battery and prevent it from being charged while conducting the experiment.

\section{V) Multimeter}

This is an electronic measuring instrument that combines several measurement functions such as voltage, current, and resistance into one unit. A digital multimeter with illuminated display and automatic display hold features was used to accurately observe the initial, intermediates, and final values of the terminal voltage in the course of the experiments.

\section{VI) AC Adapter}

This is a power adapter for converting AC to DC. Unlike the built-in supply, AC adapters are external power supply units often referred to as a charger in battery-powered appliances. They are needed for electrical appliances that do not contain the internal components required to derive the required DC voltage from the mains. Universal AC adapters were used in this research. They are designed to work with many devices since their output voltage and polarity can be switched to match a range of equipment. 
They have multiple sizes of plugs for connectivity to those devices and can automatically adjust their output voltage/maximum current according to the plug tip fitted.

\section{VII) Power Inverter}

Basically, an inverter is not a source of power but a device for changing direct current (DC) to alternating current (AC). An oscillator circuit, MOSFET drivers, and a step-up transformer are some of its key components. The oscillator generates AC signal from the 12 volt DC input voltage of the battery, while the MOSFET drivers amplify this signal which is then fed to the primary side of the step-up transformer as an input to obtain a 230 volt AC output voltage and the require power. A $12 \mathrm{~V}, 2 \mathrm{kVA}$ power inverter with overload protection was used in this research. It has a thermal detector that senses the heat generated by the step-up transformer. This heat is directly proportional to the current drawn from the transformer by the load.

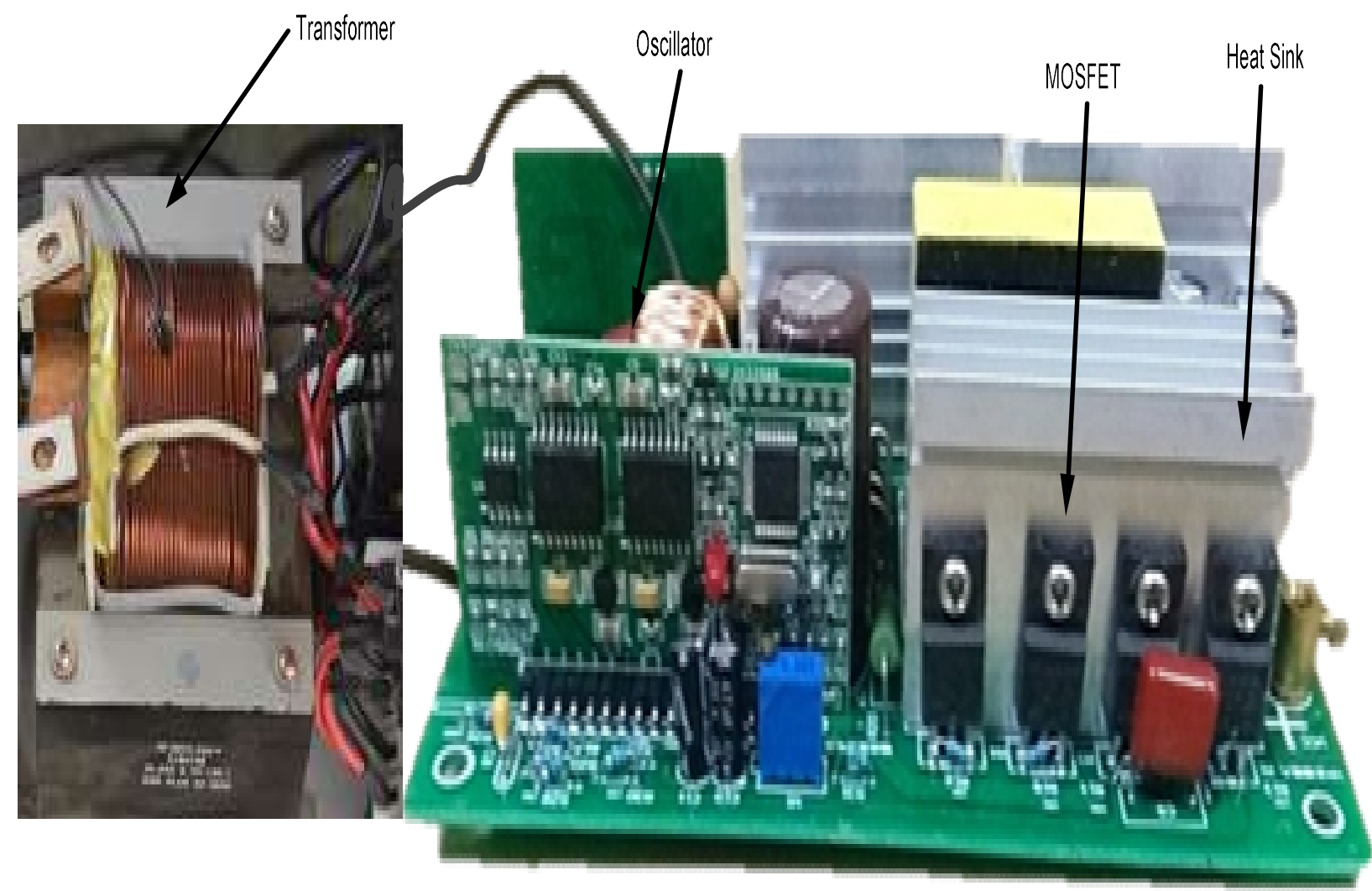

Figure 2.3: Internal View of the Inverter 


\section{RESULTS AND DISCUSSION}

From the table of values obtained during the experiments, a graph of the terminal voltage (V) against discharge time was plotted to obtain the discharge characteristic of the battery for the given loads when the inverter was connected and when it was disconnected. A comparison of the two results (Figure 3.2) shows that after six hours of usage, the battery retained more energy (as indicated by the terminal voltage) when the inverter was disconnected. As shown in figure 2.3, the transistors are mounted on heat sink for quick dissipation of heat which would affect performance of the semiconductor devices if not taken into consideration. The transformer also generates more heat as the current drawn from the output of the inverter increases. Hence, a cooling fan is often enclosed in the unit. Of course, the current increases and will continue to increase as long as DC loads are being powered from AC sources because each of the power adapter involved, whether built-in or external, is an additional load. They all contain transformers and the $I^{2} R$ loss is certain.

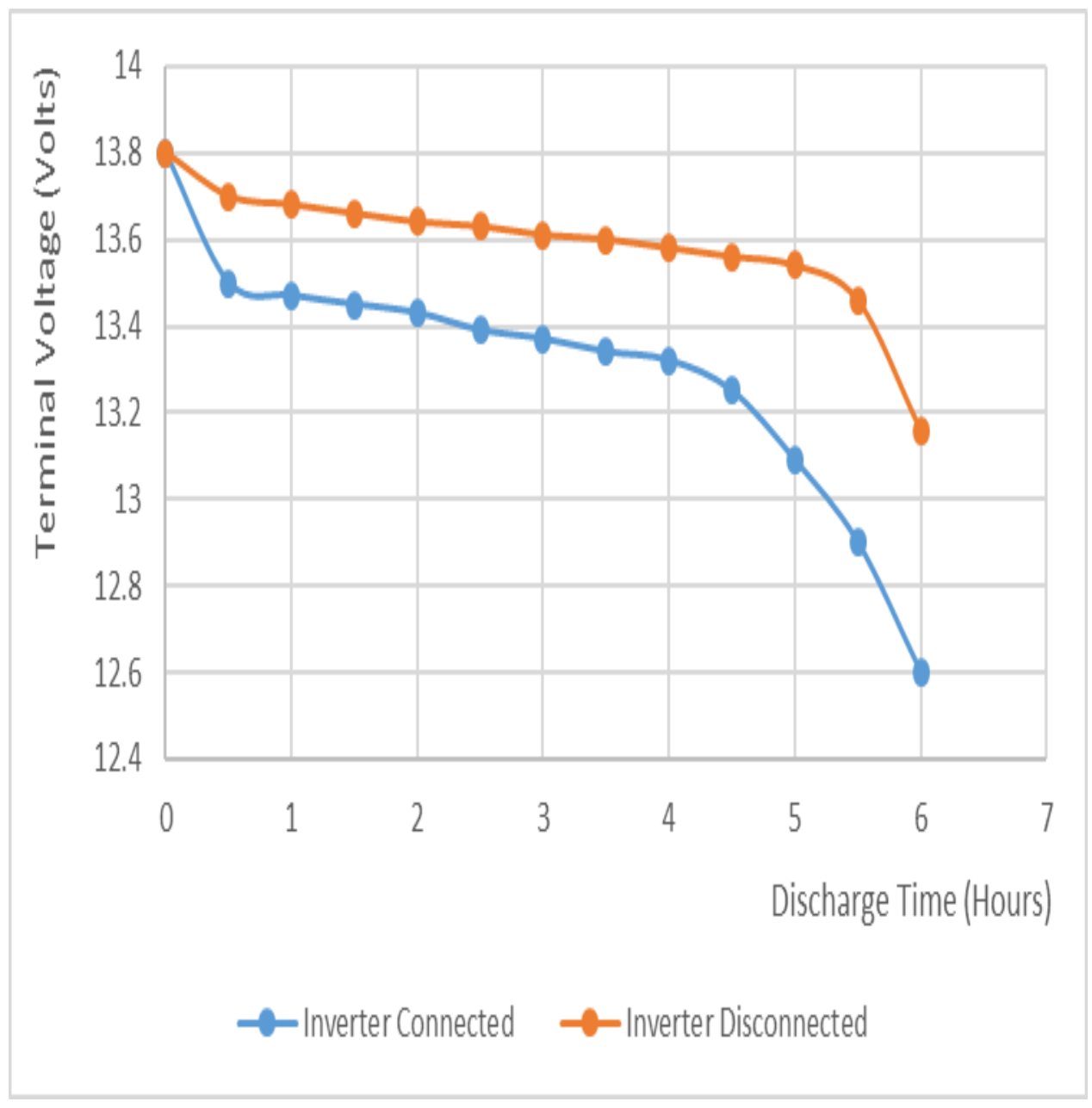

Figure 3.1: Discharge Characteristic of the Battery for Fixed Loads at $\approx 28^{\circ} \mathrm{C}$ 


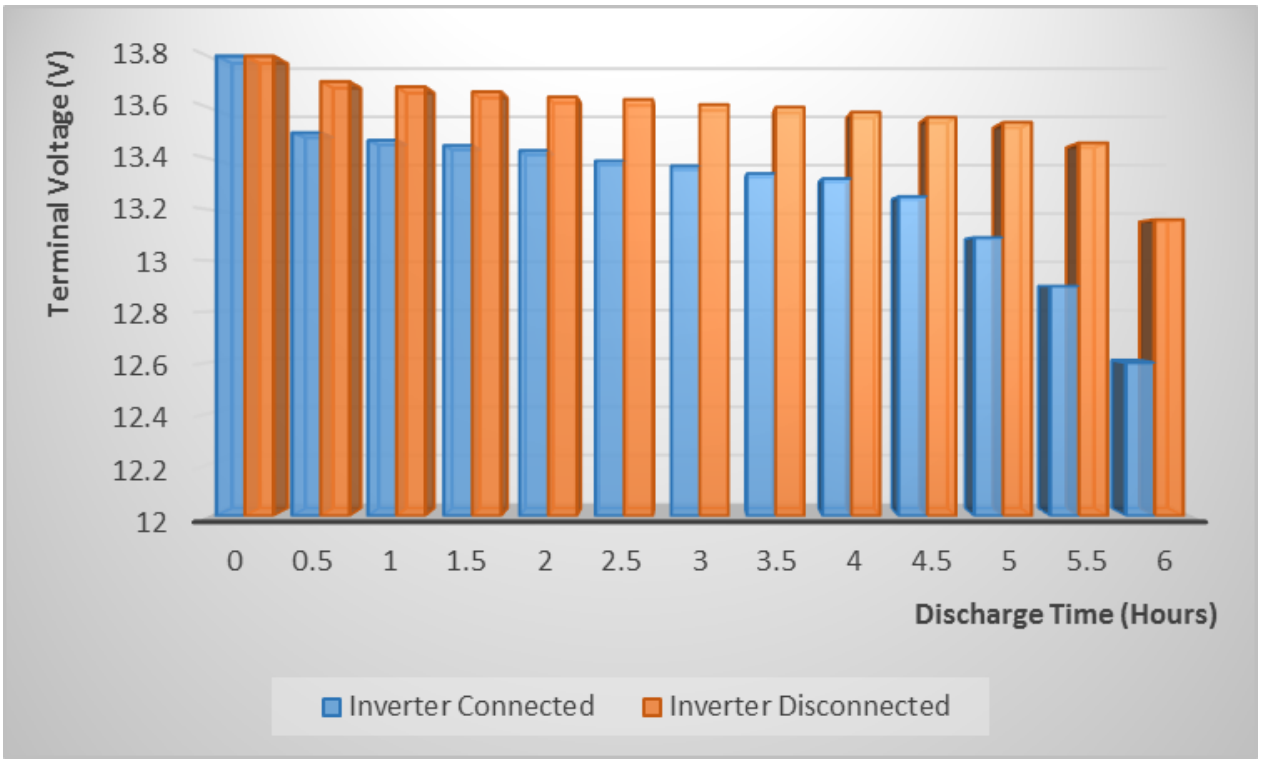

Figure 3.2: Indication of Energy Retained in the Battery

The law of conservation of energy states that the total energy of an isolated system remains constant, it is said to be conserved over time. This law means that energy can neither be created nor destroyed; rather, it can only be transformed or transferred from one form to another. However, the heat energy generated inside the inverter casing represents a proportion of the valuable energy stored in the battery and it is regarded as a source of energy wastage since it does no useful work.

\subsection{Energy-Saving Realized}

When the inverter was connected, the terminal voltage dropped by 1.2 volt within six hours of using the battery. That is, from 13.8 to 12.6 volt. But when the inverter was disconnected, the terminal voltage only dropped by 0.6volt within the same duration. That is, from 13.8 to 13.2 volt. Therefore, the percentage of energy saving achieved by connecting the loads directly to the battery is expressed as:

$$
\begin{aligned}
& \frac{1.2-0.6}{1.2} \times 100 \% \\
= & 50 \%
\end{aligned}
$$

This is an indication that the depth of discharge (D.O.D.) of the battery for a given load is doubled with the use of inverter.

That is:

With inverter connected, D.O.D. $=\frac{13.8-126}{13.8} \times 100 \%=8.7 \%$ (After six hours).

With inverter disconnected, D.O.D. $=\frac{13.8-13.2}{13.8} \times 100 \%=4.3 \%$ (After six hours). 


\section{CONCLUSION}

Electrical energy is a boon of science to the modern society, so we should be very judicious about its usage. Unless energy wastage is cut down to the minimum, there will always be a mismatch between the demand and supply of electrical energy. Since the amount of energy consumed through the use of inverter is found to be much higher than that consumed by direct usage of batteries, the difference between the two values is what this paper identifies as wasted energy. Therefore, the use of inverters for powering DC loads through DC sources such as the solar PV system should be discouraged. Wasting of our stored energy through the use of inverters would get the batteries exhausted faster. This could constrain the user to fall back on the traditional fossil fuel generator, thus bringing back the problems associated with non-renewable energy sources, e.g. pollution. Hence, for optimization of renewable energy usage, minimizing the wastage of stored energy is paramount. Although the sources of renewable energy are not just inexhaustible but also inexpensive, their availability may sometimes depend on the weather. Batteries are therefore often needed for the energy storage. Improvements on the life span and efficiency of this storage medium or a discovery of cheaper alternatives would be a laudable breakthrough.

\section{REFERENCES}

1. Brock, G; Inês Lima A; Chris, H. (Oct. 2016) "How much electricity can we save by using direct current circuits in home? Understanding the potential for electricity savings \& assessing feasibility of a transition towards DC powered buildings” Applied Energy. Vol. 180, pp. 66-75

2. Ehsanul K; et al, (Feb. 2018) "Solar Energy: Potential and Future Prospects" Renewable \& Sustainable Energy Reviews. Vol. 82, Part 1, pp. 894-900.

3. Ellabban, O; Abu-Rub, H; Blaabjerg, F. (Nov. 2014) "Renewable Energy Resources: Current Status, Future Prospects and their Enabling Technology". Renewable and Sustainable Energy Reviews. Volume 39, pp. 748-764.

4. Enrique, R.D., Juan, C.V., Josep, M.G., (Jan. 2016) "Intelligent DC Homes in Future Sustainable Energy Systems: When Efficiency and Intelligence Work Together”, IEEE Consumer Electronics Magazine, Volume 5, No. 1, pp. 74-80.

5. Garbesi, K., Vossos, V., and Shen, H., (2011) "Catalog of DC Appliances and Power Systems", Lawrence Berkeley National Laboratory, Berkeley, CA.

6. Laudani, G.A., and Paul, D.M., "Comparison of Cost and Efficiency of DC versus AC in Office Buildings", Engineering and Physical Sciences Research Council, Imperial College London.

7. Mackay, L., Ramirez-Elizondo, L., Bauer, P., (2014) "DC Ready Devices - Is Redimensioning of the Rectification Components Necessary?" 16th International Conference on Mechatronics-Mechatronika, Brno, pp.1-5.

8. Muhammad, K., Muhammad, B., Muhammad, M. (Oct. 2017) "DC Home Appliances for DC Distribution System” Mehran University Research Journal of Engineering \& Technology, Volume. 36, No. 4, pp.881-890.

9. Okoro, O. I. and Madueme, T.C.: (2006) "Solar Energy: A necessary investments in a Developing Economy”, International Journal of Sustainable Energy, vol. 25, No. 1, pp. 23-31.

10. Pang, H., Lo, E., and Pong, B., (2006) "DC Electrical Distribution Systems in Buildings", 2nd International Conference on Power Electronics Systems and Applications, Hong Kong, pp. 115-119.

11. Pertti, P., Tero, K., Jarmo, P. (June 2009) "DC Supply of Low-Voltage Electricity Appliances in Residential Buildings" C I R E D 20th International Conference and Exhibition on Electricity Distribution - Part 1, Prague. 
12. Schiermeier, Q; Tollefson, J; Scully, T; Witze, A; Morton, O. (2008) "Energy Alternatives: Electricity Without Carbon”. Nature. Volume 454, Issue 7206, pp. 816-823.

13. Schleupner, C; Schneider, U. (2010) "Effects of Bioenergy Policies and Targets on European Wetland Restoration Options”. Environmental Science \& Policy. Vol. 13, No.8, pp.721-732.

14. Soo, H.L., and Jung, W.P., (June, 2016) "Optimal Operation of Multiple DGs in DC Distribution System to Improve System Efficiency”, IEEE Transactions on Industry Applications. No. 99, pp. 11-21.

15. Starke, M., Fangxing, L., Tolbert, L.M., Burak, O., (2008) "AC vs. DC Distribution: Maximum Transfer Capability". IEEE Power and Energy Society General Meeting - Conversion and Delivery of Electrical Energy in the 21st Century. Chicago, IL, USA.

16. Starke, M., Tolbert, L.M., Burak, O., (2008). "AC vs. DC Distribution: A Loss Comparison”. IEEE/PES Transmission \& Distribution Conference \& Exposition. Chicago, IL, USA.

17. Thomas, B; Markus, B; Sabine, G; Ingrid, S. (Aug, 2013) "Energy landscapes: Meeting energy demands and human aspirations" Biomass and Bioenergy. Volume 55, pp. 3-16.

18. Vagelis, V., Karina, G., Hongxia, S., (2014) "Energy Savings from Direct-DC in US Residential Buildings”, Elsevier Transaction on Energy and Buildings, Vol. 68, pp. 223-231. 